\title{
Women for a Change: Closing the Leadership Gap
}

\author{
Sophie Soklaridis • Jenna López
}

Received: 3 April 2014 / Accepted: 18 July 2014 / Published online: 8 August 2014

(C) Academic Psychiatry 2014

In the fall of 2013, the first author (SS) attended the Association for Academic Psychiatry's annual meeting in Charleston, South Carolina. During a panel discussion on the second day, the issue of why there are so few women leaders in psychiatry did not simply emerge - it exploded, so much so that it was a challenge for the highly skilled facilitator of the discussion to move the conversation away from gender and into other areas of navigating a career as a psychiatric educator. At the workshops, conversations and questions invariably led back to this concern about the lack of women leadership in psychiatry.

Women and leadership is a hot topic, not only in the sense of its public popularity, but also in the strong beliefs and contested opinions it elicits about why so few women hold leadership positions. In post-AAP conversations, we reflected on the genuine concern expressed by conference participants who were courageous enough to speak about a topic that often provokes visceral, and sometimes vitriolic, reactions. Our conversations led us to consider how the dialogue generated during the AAP conference on the topic of women and leadership in psychiatry has deep roots in our current social and cultural environment. We discussed how a North American post-feminist culture that places such a high value on individualism influences how we develop, promote, and retain women aspiring to assume and be successful in leadership roles. The lack of women in leadership roles is not unique to psychiatry. This article provides a brief overview of feminism, post-feminism, and individualism as a means of grounding the conversation. We also offer considerations on which leaders in departments of psychiatry may reflect as they work toward maximizing female talent in their settings.

S. Soklaridis $(\varangle) \cdot J$. López

Centre for Addiction and Mental Health, Toronto, Ontario, Canada

e-mail: sophie.soklaridis@camh.ca

S. Soklaridis

Department of Psychiatry, University of Toronto, Toronto, Ontario, Canada
Feminism, Post-feminism, and Individualism

There are many "feminists" and many different theories. Modern feminism, however, can be grouped into three waves: The first wave spanned the late nineteenth century to the early twentieth century; the second wave occurred between the early 1960s and the late 1980s; and the third wave began in the early 1990s and continues today into post-feminism.

The first wave of feminism emerged in the context of industrial society, liberal politics, and the movement to abolish slavery. Its goal was to create access and equal opportunities for women, with a focus primarily on suffrage but also on access to education and health care; the right to work, possess money, and own property; and women's right to themselves and their own bodies. First-wave feminists spent years in activism that can be traced back to the Middle Ages. Most people consider the first wave to have ended when women were granted the right to vote.

Second-wave liberal feminism of the 1960s and 1970s emerged in the context of postwar Western welfare societies and the civil rights movement. The second wave focused on expanding equal opportunities for women within our existing social, economic, and political system. It was widely believed that our societal systems did not have to make any fundamental changes but only needed to be modified so that women had an equal opportunity to access these systems. This liberal approach was challenged by some radical and socialist feminists who believed in a complete overhaul of the current capitalist and patriarchal systems (including the need to problematize gender, race, class, and sexual orientation). These feminists criticized capitalism and imperialism, and focused on the notion and interests of oppressed groups: the working classes, racial minorities, and, in principle, women. A common thread among all feminists during this time, regardless of their theoretical perspective, was emphasis on the collective, 
however. Second-wave feminists strongly believed that women could collectively empower one another.

In the 1990s, third-wave feminism, some believe, emerged in response to the backlash against the contradictions that were unexpectedly created by the second wave. It challenged the notion of universal womanhood and focused on the need to develop a feminist theory and politic that captures the contradictory experiences of women. Thus, third-wave feminism focused more on women as individuals than as a collective. It represented a shift away from a hegemonic feminism that represented privileged white, middle-, and upper-class heterosexual women toward a feminism that no longer reinforced racism and classism. According to this perspective, individual empowerment is considered key to a woman's success: "Empowerment . . . not in collective terms, as with the second wave, but in very individualistic terms. Being empowered in the third-wave sense is about feeling good about oneself and having the power to make choices" [1, p. 195]. The belief that women have the power to choose to be successful and can do so by taking personal responsibility ushered in what many believe is our current ideological world of post-feminism.

Post-feminism rejects altogether the notion of gender inequalities. According to post-feminist ideology, equality between the sexes has been well established, and the playing field is level. Women have no one to blame but themselves if they do not succeed [2]. They are encouraged to persevere and work harder because their struggles are seen not as collective or political issues but as more of a lifestyle choice. Postfeminism is based on the concept of individualism, a central and defining value in North American culture. Individualism is "a belief that the individual has a primary reality, whereas society is a second-order, derived or artificial construct" [3, p. 334]. It discourages people from contextualizing their personal issues within existing systems. It does not deny that structural inequalities exist, but it demands that each person manages and overcomes her or his problems through personal psychological changes to the self. Several feminist scholars have critiqued post-feminism in its assumption and suggestion that gender equality has been achieved and that gender struggles are a thing of the past [4]. Post-feminism creates an equality illusion that obscures or makes invisible the many ways in which women continue to be underprivileged and marginalized socially, politically, and economically in many spheres, including in the workplace.

\section{Is the Playing Field Level between Men and Women?}

A post-feminist perspective argues that all is equal between women and men. This is not the case, however, according to the 2012 Global Gender Gap Report. The report ranks 135 countries on the basis of 14 indicators that measure gender gap in four key areas: economic participation and opportunity, education attainment, health and survival, and political empowerment. The indicators assess gender-based gaps in access to resources and opportunities, rather than actual levels of available resources and opportunities in individual countries [5]. According to the report, no country has yet closed its gender gap. North America has closed $74 \%$ of its gender gap and has shown significant improvements over the last 7 years (improving by $5 \%$ between 2006 and 2013).

Women's underrepresentation in academic settings, including universities and teaching hospitals internationally, has been well established [6-8]. This underrepresentation is especially true for leadership positions: the higher the rank, the more skewed the gender representation becomes [6]. In addition, women are underpaid in comparison to men who hold the same positions - a gap that cannot be explained by age or rank and may be more extreme for women of color [6].

The Nordic countries have come closer to closing the gender gap than any economy in modern history. All of the Nordic countries, except Denmark, have closed over $80 \%$ of the gender gap. It appears that Nordic countries have rejected the notion that gender equality comes from individual transformation. Leaders in these countries have taken a systemic approach to closing the gender gap. For example, these countries were early adapters in giving women the right to vote; their political parties introduced voluntary gender quotas in the 1970s that resulted in high numbers of female political representatives; and they have implemented generous maternity leave provisions and inexpensive daycare, which acknowledge women's high labor participation. As an example of a top-down approach to promoting women's leadership, publicly listed companies in Norway are required to have $40 \%$ female board membership [9].

Addressing homophily, people's preference for associating with similar others, is a strategy for closing the gender gap. For example, initiatives to increase women's participation in politics and the workforce, as described above, have somewhat addressed the issue of homophily. According to the similarity-attraction paradigm, individuals form more positive evaluations and decisions about people whom they see as most akin to themselves [10]. This preference has been called "homosocial reproduction" [11]. Kanter [11] posited a link between this preference and the attainment of leadership roles. She argued that all bureaucracies try to minimize uncertainty. Uncertainty is always present when individuals are relied upon to make decisions. One way to minimize uncertainty is to close top administration positions to individuals who are regarded as "different." As a result, women have a difficult time entering the male-dominated ranks of top management and continue to occupy only a small portion of executive positions with the greatest power and authority.

Adding to the complexity of the issue of women in leadership is the fact that the few women who occupy executive 
positions are often viewed as "tokens" by the male "dominants" [12]. As tokens, these women are seen by the rest of the group as representing their sex [11, 12]. Because tokens are more highly visible, they get attention that dominants do not get. As a result, the differences between female tokens and male dominants tend to be over-exaggerated. Women also may feel like outsiders in their workplace environment due to exclusion and feeling unwelcome, undermined, silenced, or objectified [13]. Unfair treatment of women in the workplace can have a detrimental effect on self-confidence and career achievement because women may not want to attract attention or visibility and may thus be reluctant to participate and engage in professional activities $[14,15]$.

Despite the considerable changes in women's and men's roles in the workplace and in society over the past four decades, gender stereotypes of women as exhibiting primarily feminine traits and men as possessing primarily masculine traits have remained unchanged. Similarly, stereotypes of good leaders have remained fundamentally the same despite the considerable increase in female managers [16]. A study that compared current beliefs about what characterizes a good manager with those of the past three decades found that people continue to ascribe stereotypically masculine traits to good managers. The authors concluded that "Think managerthink masculine" and "Think manager - think male" remain the dominant perspective among both men and women [17].

Discussions about women and leadership in a post-feminist era tend to focus on how to "fix" women, rather than on identifying structural issues that must be addressed to facilitate women's full participation at all levels of our institutions [18, 19]. Understanding why there are few women in leadership positions in general, and specifically in psychiatry, requires taking a balanced approach that considers not only each woman's individual responsibility to take action, but also the roles and responsibilities of institutions in creating a less "chilly climate" for women [20].

\section{What Can Departments of Psychiatry Do to Close the Gender Gap?}

Mirroring the struggles of women in greater society, women physicians are tasked with overcoming social and institutional obstacles to achieve acceptance and representation [21, 22]. Although more women are pursuing careers in medicine and psychiatry, there has not been a corresponding increase in the number of women in leadership positions in these fields. Two patterns of underrepresentation have emerged. First, women are less likely than men to move into professional positions, especially leadership roles, within their field. Second, women are underrepresented relative to their share of the general population in all levels of a profession [23]. The situation in academic psychiatry reflects the first pattern. In the USA, half of all medical students and residents and one third of full-time faculty are women, yet women remain largely underrepresented in leadership [24]. In 2011, there were no permanent leadership positions in which the proportion of women was greater than that of men in academic medicine. Women make up $22 \%$ of division and section chiefs, $22 \%$ of associate and vice-chairs, $14 \%$ of department chairs, and $12 \%$ of decanal positions [24].

Several systemic strategies could help psychiatry to close the gender gap in leadership. Increasing the representation of women in leadership roles in academic and hospital settings has been on the agenda of universities and governments for a long time. For example, Canada lays out gender-equity goals in the Employment Equity Act, the Canadian Human Rights Act, and the UN Convention on the Elimination of All Forms of Discrimination against Women, but these goals are not currently being met [25-27].

\section{Gender Diversity Policy}

Among the many approaches to change is the implementation of policies governing the hiring process, such as legislative quotas and employment-equity policies. Departments of psychiatry could implement a gender-diversity policy that reflects the department's commitment to maximizing female talent and creating a more balanced gender composition. Such a policy could provide measurable objectives for achieving gender diversity. The gender diversity policy could be publicly disclosed in reporting structures and/or on departmental websites, along with data about the proportion of women employees in the organization who hold senior executive positions. Departmental leaders could also demonstrate forward thinking by stating where they would like to see the proportion of women leaders in the next 5 years.

Although there may be some skepticism about the effectiveness of policies in promoting social change, they have been shown to play a role in breaking through the glass ceiling for women in academia [28]. In addition, recent studies have found that companies with a more balanced gender composition are more innovative than companies with a high concentration of one gender [29, 30]. Increased innovation is reason enough for academic departments to recognize and value gender diversity. A department's innovativeness may also increase its ability to recruit and retain individuals with promise and talent.

\section{Gender Quotas}

People in leadership positions could address homophily by implementing gender quotas in hiring, retaining, promoting, and developing women leaders. We know that the use of a 
quota system to improve gender and demographic diversity in organizations is often met with mixed reactions. Several popular misconceptions have surrounded gender quotas: (1) the playing field is now level, so we do not need gender quotas; (2) the public does not support the use of gender quotas; and (3) white males will "lose out" if gender quotas are implemented. These misconceptions have proved to be more myth than fact [31, 32].

Quotas are designed to rectify the extreme gender imbalance that persists despite female advancements in education and workforce participation. In fact, quotas have been so successful in Denmark that they are no longer needed to maintain and retain women leaders in politics. For those who argue against the use of quotas, take a moment to reflect on this question: If women have been part of the professional and managerial ranks since the 1970 s, then why, almost half a century later, are only $4 \%$ of Fortune 500 CEO positions held by women [33]? Further, why do $10 \%$ of Fortune 500 companies have no women on their boards, and why do two thirds have no women of color on their boards [34]?

In addition to enforcing a quota system, psychiatry departments need to pay careful attention to the informal processes of exclusion and devaluation that impede women's achievements $[14,35]$. Gender inequality practices are pervasive, long-standing, and often well hidden and are carried out through micropolitics that are difficult to address through policy $[7,8]$. Research has shown that policies intended to address gender inequality are often not well implemented, monitored, or enforced $[8,36]$. Implementing new policy should be one part of a larger strategy to address gender inequality.

\section{Mentorship Programs}

Departments of psychiatry could address the "Think manager-think male" perspective by implementing programs that encourage female networking, mentoring, and role modeling. Women face structural constraints in developing personal networks because homophily strongly influences network formation [37, 38]. Most departments of psychiatry across North America are male dominated. This means that women have fewer opportunities to develop homophilous ties within their colleagues and rely more on heterophilous ties, which tend to be weaker and are more subject to disruption [39]. Faculty mentoring and informal conversations about research take place within the informal networks of a department. The absence of ties to these informal networks creates a perception of exclusion.

Mentorship research emphasizes having or being a mentor and having identifiable role models as essential to advancement into leadership positions [40-43]. Despite the potential benefits, many women in academic health systems do not have adequate mentorship [42, 44]. When they are mentored, they often report negative mentoring relationships. One study found that female mentees in psychiatry are less likely to be encouraged by their mentors to participate in outside professional activities, are three times more likely to have mentors take credit for female mentees' work, and frequently perceive their mentors as negative role models [45]. In addition, women in positions of authority found that their attempts to provide individual mentoring to others were ignored or even thwarted. For example, female chairs in medical schools found that males, as well as females, under their leadership were more resistant to reporting to them or accepting their leadership styles and decision-making [46].

Women physicians struggled to balance the pursuit of education and expertise with the societal expectations to reproduce and be responsible for family life [21, 22]. Departments of psychiatry could establish mentorship programs that emphasize understanding the role that gender plays in a hierarchical academic environment. Such programs might bridge some of the gaps women experience within informal departmental networks. They could also provide future women leaders with opportunities for socialization, skills building, networking, and brainstorming around how to balance professional and personal demands.

\section{Conclusion}

Women are more likely than men to perceive that their gender is a cause of inequitable treatment [47]. We have provided an overview of how post-feminist notions of individualism discourage people from contextualizing their personal issues within existing systems. Despite the belief in a level playing field, a gender gap does exist that is maintained through homophily, tokenism, and gender stereotypes in leadership. Serious structural barriers impede progress toward greater gender diversity. We have suggested various ways in which departments of psychiatry can create a more inclusive environment for women. Leadership needs to consider policy changes, quotas, and formal mentoring programs to address the challenges that women face in reaching senior-level positions.

Implications for Academic Leaders

- Women are underrepresented in leadership roles in departments of psychiatry across North America.

- Gender-diversity policies, gender quotas in hiring, and retention/ promotion strategies could be used to maximize female talent and create a more balanced gender composition.

- Current leadership must reflect on the informal processes of exclusion, devaluation, and micropolitics that impede women's achievements. 
Acknowledgments The authors would like to acknowledge and express their gratitude to Hema Zbogar for her expert editing and assistance in the preparation of this manuscript. We would also like to thank the reviewers for their thoughtful comments that served to strengthen the paper.

Disclosure On behalf of the authors, Dr. Sophie Soklaridis states that there is no conflict of interest.

\section{References}

1. Shugart HA, Egley Waggoner C, O’Brien Hallstein DL. Mediating third-wave feminism: Appropriation as postmodern media practice. Crit Stud Media Comm. 2001;18:194-210.

2. Vavrus MD. Postfeminist news: Political women in media culture. New York: SUNY Press; 2002.

3. Bellah RN, Madsen R, Sullivan WM, et al. Habits of the heart: Individualism and commitment in American life. Berkeley: University of California Press; 2007.

4. McRobbie A. The aftermath of feminism: Gender, culture and social change. London: Sage; 2008.

5. Hausmann R, Tyson LD, Zahidi S. The global gender gap report 2012. World Economic Forum. 2012. Retrieved from http://www3. weforum.org/docs/WEF_GenderGap_Report_2012.pdf

6. Council of Canadian Academies. Strengthening Canada's research capacity: the gender dimension. The Expert Panel on Women in University Research. Council of Canadian Academies. 2012. Retrieved from www.scienceadvice.ca/en/assessments/completed/ women-researchers.aspx

7. Morley L. Hidden transcripts: the micropolitics of gender in Commonwealth universities. Women Stud Int Forum. 2006;29: 543-51.

8. van den Brink M, Benschop Y, Jansen W. Transparency in academic recruitment: a problematic tool for gender equality? Organ Stud. 2010;31(11):1459-83.

9. Sweigart A. Women on board for change: the Norway model of boardroom quotas as a tool for progress in the United States and Canada. NJILB. 2012;32(4):81A-105.

10. Byrne D, Neuman JH. The implications of attraction research for organizational issues. In: Kelley $\mathrm{K}$, editor. Issues, theory, and research in industrial/organizational psychology. Amsterdam: Elsevier; 1992. p. 29-70.

11. Kanter RM. Men and women of the corporation. New York: Basic Books; 1977.

12. Kanter RM. Some effects of group proportions on group life: Skewed sex ratios and responses to token women. Am J Sociol. 1977;82:96590.

13. Fotaki M. No woman is like a man (in academia): the masculine symbolic order and the unwanted female body. Organ Stud. 2013;34(9):1251-75.

14. Morley L. Organising feminisms: the micro-politics of the academy. Basingstoke: Macmillan; 1999.

15. Seymour E, Hewitt NM. Talking about leaving: why undergraduates leave the sciences. Boulder: Westview Press; 1997.

16. Powell GN. The gender and leadership wars. Organ Dyn. 2011;40:19.

17. Powell GN, Butterfield DA, Parent JD. Gender and managerial stereotypes: have the times changed? J Manag Dev. 2002;28:177-93.

18. Agars MD, Kottke JL. Models and practice of diversity management: a historical review and presentation of a new integration theory. In: Stockdale M, Crosby F, editors. The psychology and management of workplace diversity. Oxford: Blackwell; 2004. p. 55-77.
19. Kottke JL, Agars MD. Understanding the processes that facilitate and hinder efforts to advance women in organizations. Career Dev Int. 2005; 10:190-202.

20. Sandler B. The chilly climate revisited: Chilly for women faculty, administrators and graduate students. Washington, DC: Association of American Colleges; 1986.

21. Morantz-Sanchez RM. Sympathy and science: women physicians in American medicine. New York: Oxford University Press; 1985.

22. More, ES. Restoring the balance: women physicians and the profession of medicine, 1850-1995. Cambridge, Mass: Harvard University Press; 2009.

23. Ontario Confederation of University Faculty Associations. Data check: women still underrepresented in Canadian universities. Ontario Confederation of University Faculty Associations. 2012. Retrieved from http://ocufa.on.ca/2012/data-check-women-stillunderrepresented-in-canadian-universities/\#sthash.uanpGtST.dpuf

24. Joliff L, Leadley J, Coakley E, et al. Women in U.S. academic medicine and science: Statistics and benchmarking report, 20112012. Washington, DC: Association of American Medical Colleges; 2012.

25. Department of Justice Canada. Employment Equity Act. 1995. Retrieved from http://laws-lois.justice.gc.ca/PDF/E-5.401.pdf

26. Department of Justice Canada. Canadian Human Rights Act. 1985. Retrieved from http://laws-lois.justice.gc.ca/PDF/H-6.pdf

27. Convention on the Elimination of All Forms of Discrimination against Women. 1981. Retrieved from www.un.org/womenwatch/ daw/cedaw/cedaw.htm

28. Timmers T, Willemsen T, Tijdens K. Gender diversity policies in universities: a multi perspective framework of policy measures. High Educ. 2010;59(6):719-35.

29. Diaz-Garcia C, Gonzalez-Moreno A, Saez-Martinez J. Gender diversity within R\&D teams: its impact on radicalness of innovation. Innov-Manag Policy Pract. 2013;15(2):149-60.

30. Ostergaard CR, Timmermans B, Kristinsson K. Does a different view create something new? The effect of employee diversity on innovation. Res Policy. 2011;40:500-9.

31. Fryer RG, Loury GC. Affirmative action and its mythology. J Econ Perspect. 2005;19:147-62.

32. Fryer RG, Loury GC, Yuret T. An economic analysis of color-blind affirmative action. J Law Econ Organ. 2008;24:319-55.

33. Catalyst. Women in U.S. management and labor force. 2013. Retrieved from www.catalyst.org/knowledge/women-usmanagement-and-labor-force

34. Catalyst. Catalyst 2013 census of Fortune 500: still no progress after years of no progress. 2013. Retrieved from www.catalyst.org/media/ catalyst-2013-census-fortune-500-still-no-progress-after-years-noprogress

35. van den Brink M, Benschop Y. Gender practices in the construction of academic excellence: Sheep with five legs. Organization. 2012;19: 507-24.

36. Gatrell C. Managing the maternal body: a comprehensive review and transdisciplinary analysis. Int J Manag Rev. 2011;13:97-112.

37. Ibarra H. Personal networks of women and minorities in management: a conceptual framework. Acad Manag Rev. 1993;18(1):56-87.

38. Mehra A, Kilduff M, Brass D. At the margins: a distinctiveness approach to the social identity and social networks of underrepresented groups. Acad Manag J. 1998;41(4):441-52.

39. South SJ, Bonjean C, Markham W, et al. Social structure and group interaction: Men and women of the federal bureaucracy. Am Sociol Rev. 1982;24:367-80.

40. DeFrancisci LL, Wood WC, Petkova E, et al. Mentoring in psychiatric residency programs: a survey of chief residents. Acad Psychiatry. 2009;33(4):307-12.

41. Frei E, Stamm M, Buddeberg-Fischer B. Mentoring programs for medical students: a review of the PubMed literature, 2000-2008. BMC Med Educ. 2010;10(32). doi:10.1186/1472-6920-10-32. 
42. Sambunjak D, Straus SE. Mentoring in academic medicine: a systematic review. JAMA. 2006;296(9):1103-15.

43. Wise MR, Shapiro H, Bodley J, et al. Factors affecting academic promotion in obstetrics and gynaecology in Canada. J Obstet Gynaecol Can. 2004;26(2):127-36.

44. Bickel J, Wara D, Atkinson BF, et al. Increasing women's leadership in academic medicine: Report of the American Association of Medical Colleges Project Implementation Committee. Acad Med. 2002;77(10):1043-61.
45. Bickel J. Women in academic psychiatry. Acad Psychiatry. 2004;28(4):285-91.

46. Yedidia MJ, Bickel J. Why aren't there more women leaders in academic medicine? The views of clinical department chairs. Acad Med. 2001;76(5):453-65.

47. Mor Barak M, Cherin D, Berkman S. Organizational and personal dimensions in diversity climate: Ethnic and gender differences in employee perceptions. J Appl Behav Sci. 1998;34(1):82-104. 